\title{
Bronchopulmonary dysplasia: clinical aspects and preventive and therapeutic strategies
}

\author{
Nicola Principi ${ }^{1}$, Giada Maria Di Pietro ${ }^{1}$ and Susanna Esposito ${ }^{2^{*}}$
}

\begin{abstract}
Background: Bronchopulmonary dysplasia (BPD) is the result of a complex process in which several prenatal and/ or postnatal factors interfere with lower respiratory tract development, leading to a severe, lifelong disease. In this review, what is presently known regarding BPD pathogenesis, its impact on long-term pulmonary morbidity and mortality and the available preventive and therapeutic strategies are discussed.

Main body: Bronchopulmonary dysplasia is associated with persistent lung impairment later in life, significantly impacting health services because subjects with BPD have, in most cases, frequent respiratory diseases and reductions in quality of life and life expectancy. Prematurity per se is associated with an increased risk of long-term lung problems. However, in children with BPD, impairment of pulmonary structures and function is even greater, although the characterization of long-term outcomes of BPD is difficult because the adults presently available to study have received outdated treatment. Prenatal and postnatal preventive measures are extremely important to reduce the risk of BPD.

Conclusion: Bronchopulmonary dysplasia is a respiratory condition that presently occurs in preterm neonates and can lead to chronic respiratory problems. Although knowledge about BPD pathogenesis has significantly increased in recent years, not all of the mechanisms that lead to lung damage are completely understood, which explains why therapeutic approaches that are theoretically effective have been only partly satisfactory or useless and, in some cases, potentially negative. However, prevention of prematurity, systematic use of nonaggressive ventilator measures, avoiding supraphysiologic oxygen exposure and administration of surfactant, caffeine and vitamin A can significantly reduce the risk of BPD development. Cell therapy is the most fascinating new measure to address the lung damage due to BPD. It is desirable that ongoing studies yield positive results to definitively solve a major clinical, social and economic problem.
\end{abstract}

Keywords: Bronchopulmonary dysplasia, Lung, Prematurity, Preterm neonates, Respiratory disease, Respiratory tract infection

\section{Background}

Preterm birth has been associated with an increased risk of early and late severe clinical problems, including poor adult health. Complications are very common in extremely preterm (EPT; i.e., $<28$ weeks of gestational age) and very preterm infants (VPT; i.e., 28-31 weeks of gestational age), but

\footnotetext{
*Correspondence: susanna.esposito@unimi.it; susanna.esposito@unipg.it

2 Pediatric Clinic, Department of Surgical and Biomedical Sciences,

Università degli Studi di Perugia, Piazza Menghini 1, 06129 Perugia, Italy Full list of author information is available at the end of the article
}

complications can also occur in modestly preterm infants (MPT; i.e., $\geq 32$ weeks of gestational age) [1-3]. Together with chronic neurological diseases, chronic respiratory problems due to bronchopulmonary dysplasia (BPD) are the most common long-term complications of prematurity [4, 5]. BPD is the result of a complex process in which several prenatal and/or postnatal factors interfere with lower respiratory tract development, leading to a severe, lifelong disease.

When BPD was identified as a clinical problem, most patients with EPT and VPT did not survive. This clinical 
condition was diagnosed mainly in MPT and was considered the consequence of an inadequate therapeutic approach to neonatal respiratory distress syndrome (RDS) [6]. RDS is a respiratory disorder chiefly of newborn premature infants that is characterized by deficiency of the surfactant coating the inner surface of the lungs resulting in labored breathing, lung collapse, and hypoxemia. When survival of EPT and VPT became more common because of the introduction of prenatal steroid administration, postnatal surfactant supplementation, and safer ventilator measures, it was shown that BPD had a frequency inversely correlated with gestational age and could be associated with inadequate postnatal therapy only in a minority of cases. By contrast, it was shown that, in most cases, BPD was the consequence of a deviation from the normal lung developmental pattern, in which prematurity per se and a number of potentially interfering factors, including genetics, could play causative roles [7]. However, independent of its origin, it is presently clearly established that BPD is associated with persistent lung impairment later in life, significantly impacting health services because subjects with BPD have, in most cases, frequent respiratory diseases and reductions in quality of life [8].

Fortunately, in recent years, the characteristics of lung development have been better defined. Moreover, most of the factors that favour BPD development have been identified [6-10]. Despite the fact that not all of the problems related to the relationships of foetal and neonatal lung damage with later respiratory problems have been clarified, a number of effective preventive and therapeutic management strategies with potential reductions in BPD complications have been developed. In this review, what is presently known regarding the impact of BPD on long-term pulmonary morbidity and mortality and the available preventive and therapeutic strategies are discussed.

\section{The two types of bronchopulmonary dysplasia (BPD)}

According to Jobe [11], "the injury resulting in BPD likely begins as altered lung development before delivery in many infants and can be initiated by resuscitation at birth and then amplified by postnatal exposures". The timing, type and duration of exposures, together with the genetic characteristics of the child, influence the pattern of lung damage that can occur. BPD as initially described (i.e., old BPD) was considered the result of an aggressive mechanical ventilator approach in terms of peak pressures and oxygen concentrations on a relatively mature lung lacking surfactant (i.e., $\geq 32$ weeks of gestation) [12]. Several experimental studies have clearly shown that ventilation with high positive pressure and excess volume can lead to alveolar damage and severe local inflammation, with higher than normal tumour necrosis factor- $\alpha$, interleukin
(IL)-1 $\beta$, interleukin-6, and macrophage inflammatory protein-2 concentrations in the lung $[13,14]$. Moreover, aggressive ventilation has been associated with reactive oxygen species (ROS) production. Maturation of antioxidant enzyme capacities is gradual during foetal life, and some enzymes, such as catalase and copper-zinc superoxide dismutase, are significantly induced by breathing air after birth [15], indicating that even a slight increase in reactive oxygen species in moderately preterm babies can lead to lung damage [12-14]. Moreover, in experimental animals, supraphysiological oxygen concentrations during the first days of life were found to be able to compromise alveolarization and lead to right ventricular hypertrophy, vascular remodelling, and the development of small airways disease, smooth-muscle hypertrophy, and oxidative stress [16]. Similar findings were shown in lung tissue sections of neonates born before term who developed respiratory distress syndrome and were treated with high oxygen concentrations and aggressive ventilation [17].

Thanks to improvements in neonatal intensive care, both the pathogenesis and the histology of BPD have changed, and a new type of BPD has developed. More preterm infants born in the early stages of lung development presently suffer from BPD, with a frequency inversely correlated with gestational age. Most cases of BPD occur in babies born before the 32nd week of gestation, when the lung is in the canalicular (from the 17th to 26th week of gestation) or saccular (from the 27th to 36th week of gestation) stage of development [17]. Particularly in EPT, the lung structure is very immature. The respiratory bronchioles, precapillaries and mucous glands in the bronchi are not completely developed, the interstitium has not thinned adequately to form the blood-air barrier, and surfactant production by the lung epithelial cells has not started. Moreover, when preventive and therapeutic measures, such as antenatal steroid and postnatal surfactant administration, are used, even subjects born several weeks before term often develop mild to moderate respiratory problems. Unfortunately, several factors can interrupt lung development, reducing pulmonary microvascular growth and alveolarization. Practically, when foetal or postnatal factors, together with genetic predisposition, interact with a lung in early development, the development is altered, and a new type of BPD (i.e., new BPD) occurs. The already cited mechanical trauma and oxygen toxicity again play roles, but several different exposures, both prenatal and/or postnatal, are involved in this altered lung development. Maternal smoking and hypertension have been found to be associated with a twofold increase in the odds of developing new BPD [18]. Infections can have similar effects, although results of the studies specifically planned in this regard were in 
some cases partly conflicting. The relationship seems well defined for postnatal infections. Lapcharoensap et al., in a retrospective, population-based cohort study, examined whether reductions in rates of nosocomial infection were associated with changes in rates of BPD [19]. Adjusted rates of nosocomial infections and BPD from a baseline period (2006-2010) were compared with a later period (2011-2013). A total of 22,967 infants were included in the study. From the first to second period, the incidence of nosocomial infections decreased from 24.7 to $15 \%$, and BPD decreased from 35 to $30 \%$. Adjusted hospital rates of BPD and nosocomial infections were correlated positively with a calculated $8 \%$ reduction in BPD rates attributable to reductions in nosocomial infections. Similar findings were reported when the role of sepsis was considered [20]. More controversy, however, exists regarding the relevance of chorioamnionitis. In a meta-analysis of 57 studies enrolling more than 15,000 subjects, it was found that, considering together all the cases of chorioamnionitis regardless of type, infants born to mothers with this condition had a risk of developing BPD only slightly higher than that of controls (weighted mean differences [WMD] 1.89; 95\% confidence interval [CI] 1.52.3). The association remained significant for histological (WMD 2.19; 95\% CI 1.7-2.7) but not for other types of chorioamnionitis. Moreover, the conclusion of the metaanalysis was considered highly debatable mainly because most of the included studies had poor methodological quality [21]. However, a recent retrospective cohort study, in which it was evaluated whether chorioamnionitis affected the incidence of BPD after accounting for the increased risk of death, showed that prenatal infection was significantly associated with BPD and perinatal death (odds ratio [OR] 5.18; 95\% CI 4.39-6.11] [22]. A role also seemed to be played by growth restriction. Neonates small for their gestational age were found to have a more than a two times higher risk (OR 2.73; 95\% CI 2.11-3.55) of BPD development than subjects with weight appropriate for their gestational age [23]. Moreover, poor nutrition in the first days of life has been found to be associated with an increased risk of BPD [24]. Finally, genetics might contribute to BPD development. In a study conducted in twins [25], it was shown that, among monozygotic twin pairs, the observed concordance for BPD was significantly higher than the expected concordance. After controlling for covariates, genetic factors accounted for $53 \%$ of the variance in predisposition to BPD. Moreover, it was reported that the SPOCK2 gene might be considered a new possible candidate susceptibility gene for BPD because its lung expression pattern points towards a potential role in alveolarization [26]. However, the role of genetics requires further evaluation. A large genome-wide association study enrolling more than 1700 neonates did not identify genomic loci or pathways that could account for the previously described heritability of BPD [27].

In comparison with old BPD, new BPD has more severe alveolar damage, fewer severe arterial/arteriolar vascular lesions, and negligible airway epithelial lesions [28-31].

\section{Definition and prevalence of bronchopulmonary dysplasia (BPD)}

Initially, BPD was defined simply by considering the need for oxygen 28 days after birth [6]. However, in a study in which the follow-up records of 605 infants with birth weights less than $1500 \mathrm{~g}$, with data available for 2 years after birth, were examined, it was shown that the need for oxygen at 28 days was a good predictor of abnormal findings in infants with a gestational age $\geq 30$ weeks at birth, but it became less useful as gestational age decreased. Irrespective of gestational age at birth, the requirement for additional oxygen at 36 weeks of corrected postnatal gestational age was found to be a better predictor of respiratory problems. Moreover, normal respiratory outcomes were demonstrated in $90 \%$ of infants not receiving oxygen at this corrected gestational age [32].

However, a definition based on the need for oxygen or the tolerance of room air at 36 weeks of life was also not considered fully appropriate because oxygen administration might vary according to clinical practice among different centres, and BPD severity was not categorized. Several attempts to propose more appropriate definitions have been undertaken, and some of them were used clinically and for research purposes [7]. The most frequently used definition differentiates EPT from VPT. All cases are examined at 28 days, whereas a second evaluation is performed at 36 weeks for EPT and at 56 days for VPT. $\mathrm{BPD}$ is diagnosed in all preterm infants who needed oxygen at 28 days. However, BPD is considered mild if, at the time of the final evaluation, the child can tolerate room air, moderate if he or she requires $<30 \%$ oxygen and severe if $>30 \%$ oxygen is required. Need for nasal CPAP or mechanical ventilation further supports the definition of severe BPD [33].

However, even this classification cannot be considered fully satisfactory because it considers only the simplest therapeutic aspects and not the multiplicity of measures presently used in neonatal intensive care units. Moreover, it seems likely that the risk of developing long-term lung dysfunction could be more precisely predicted were circulatory problems that follow premature birth considered. As evidenced by Day and Ryan [34], subclinical vascular disease might play a role in influencing lung development, and both prenatal and postnatal factors might differently influence 
angiogenesis. Increased knowledge of these aspects of lung development might lead to the identification of a number of biomarkers able to indicate the degree of damage and the risk of later respiratory problems. Supporting this hypothesis is the evidence that prematurity is associated with suppression of vascular endothelial growth factor and induction of angiopoietin 2 [35-37]. Moreover, prematurity and mechanical ventilation have been strictly correlated with the regulation of angiogenesis through the activity of endoglin and matrix metalloproteinase $9[38,39]$.

Regarding frequency, the different definitions used to identify BPD make it difficult to evaluate the real incidence of the condition and to compare variations over time. However, several studies have suggested that, with the increase in survival rates of EPT and VPT, the incidence of children with BPD has remained quite similar to that initially calculated, although mortality has decreased due to the improved prophylactic and therapeutic measures presently available. Recent evaluations in the USA have indicated that BPD develops in approximately $10 \%$ of VPT and in $40 \%$ of EPT when the need for oxygen at 36 weeks of postmenstrual age (i.e., the time elapsed between the first day of the last menstrual period and birth plus the time elapsed after birth) is considered to identify BPD [38], indicating that, in the USA each year, approximately $5000-10,000$ new cases of the disease are diagnosed. In Europe, it was found that $10-20 \%$ of all infants born between 23 and 31 weeks of postmenstrual age developed BPD [40, 41].

\section{Long-term outcomes of bronchopulmonary dysplasia (BPD)}

Prematurity per se is associated with an increased risk of long-term lung problems. However, in children with BPD, impairment of pulmonary structures and function is even greater, although the characterization of longterm outcomes of BPD is difficult because the adults presently available to study have received outdated treatment.

\section{Persistence of lung structural alterations}

Bronchopulmonary dysplasia is associated with an increased risk of persistent lung anatomical and functional alterations in patients with both old and new BPD. Regarding anatomical damage, several studies have shown that most subjects with old BPD, when evaluated during adolescence or adulthood, had significant alterations on chest computed tomography (CT) scans [31, 42-45]. Good examples in this regard are the studies by Aukland et al. [42] and Wong et al. [43]. The first authors used high-resolution CT (HRCT) to study the lung characteristics of a cohort of 10- to 18-year-old subjects born at a gestational age of $\leq 28$ weeks or with a birth weight $\leq 1000 \mathrm{~g}$ who received prolonged oxygen treatment or were diagnosed with old BPD. The presence of the following variables was studied: linear and subpleural triangular opacities, decreased lung attenuation (on inspiration and/or expiration), bronchial wall thickening, bronchus-to-artery-diameter ratio, bullae, emphysema, collapse/consolidation and bronchiectasis. Each lobe was scored according to either the presence or absence of each of the aforementioned variables in any lung segment. Pathological findings were detected in $86 \%$ of children and adolescents, mainly the presence of linear/triangular opacities, which were seen in $82 \%$ of cases. Compared with subjects without BPD or with only mild $\mathrm{BPD}$, subjects with a history of moderate or severe BPD had significantly higher total HRCT scores (mean 3.0 vs $5.2 ; \mathrm{p}=0.009)$, as well as more opacities $(\mathrm{p}=0.035)$ and hypoattenuated areas $(\mathrm{p}=0.007)$. The very high frequency of HRCT pathological findings was also evidenced by Wong et al. [43], who studied adults born preterm and for whom a diagnosis of BPD had been made. The only difference with the study by Aukland et al. [42] was the frequency with which the various HRCT findings were detected. In the study by Wong et al. [43], among HRCT alterations, pulmonary emphysema was the most common and was detected in $71 \%$ of cases.

Studies regarding persistent anatomical alterations in subjects with new BPD have been few. Moreover, compared with studies conducted in subjects with old BPD, they included younger subjects. However, the conclusions were quite similar, clearly showing that, despite advances in neonatal care, persistent lung lesions remained very common. Mahut et al. reported the HRCT results of 41 very low birth weight infants with new BPD between 10 and 20 months old [46]. Despite advances in neonatal care, many CT findings in infants with BPD were similar to those observed in the pre-surfactant era and were still associated with the durations of supplemental oxygen and mechanical ventilation. All of the CT scans were abnormal, with linear and triangular subpleural opacities and hyperlucent areas seen on the vast majority of scans.

\section{Persistence of lower respiratory tract functional abnormalities}

Together with structural persistent modifications, BPD can be associated with significant functional alterations of the lower respiratory tract. This association was shown in younger infants, in school-aged children, in adolescents and in adults, clearly showing that intrauterine and neonatal lung damage can persist and worsen into adulthood. Respiratory impairment was found as 
a consequence of both old and new BPD. Comparisons between studies are difficult because of the different criteria used to define BPD and, among studies of only old or new BPD, because of variations in the study design, age of enrolled patients and study end points used to measure pulmonary outcomes. However, in most of the cases, a significant impact of BPD was shown. Regarding old BPD, Hakulinen et al. examined 42 children 6-9 years old, among whom 10 had a history of BPD, 19 had received neonatal respiratory treatment but had no history of BPD, and 13 had no severe neonatal respiratory problems [47].

The BPD children had markedly lower specific airway conductance and larger residual volumes than the fullterm control group, although there were no significant differences in spirometric measurements. By contrast, pulmonary function variables in prematurely born children who did not receive ventilator treatment did not differ from those in the full-term control group. Northway et al. compared in a case-control study the pulmonary function of 52 adolescents and young adults born prematurely (26 with BPD) with that of 53 healthy controls born at term [48]. The authors reported that $68 \%$ of the subjects with BPD had airway problems [lower forced vital capacity (FVC), lower forced expiratory volume in $1 \mathrm{~s}$ (FEV1) and lower forced expiratory flow between 25 and $75 \%$ of vital capacity (FEF25\%-75\%) than individuals included in the preterm group without BPD and term controls. Furthermore, $24 \%$ of the subjects with old BPD had fixed airway obstruction, and $52 \%$ had reactive airway disease, as indicated by their responses to the administration of methacholine or a bronchodilator.

Details on the short- and long-term respiratory outcomes of new BPD can be derived from the paper by Islam et al., who reviewed all of the literature on this topic published during or since 1990 [49]. Because the greatest part of the studies analysed by these authors were conducted after the routine use of prenatal steroids and the availability of surfactant, it is highly likely that the conclusions of this review apply mainly to new BPD. Airway obstruction was the most important finding in most of the studies, and it was demonstrated in the first controls after the few months of life and persisted over time. Baraldi et al. reported that children with BPD, examined at 2 years of age, showed a substantial improvement in pulmonary mechanics but still presented with a substantially low FEF [50]. Robin et al. compared the respiratory function of 28 preterm infants with BPD and 41 healthy, fullterm subjects and found that BPD was associated with mild to moderate airflow obstruction and air trapping [51]. In particular, these authors reported decreased FEFs, including FEV in $0.5 \mathrm{~s}$, forced FEF at $75 \%$ and FEF $25-75 \%$ in children with disease, compared to controls. Fakhoury et al. prospectively and longitudinally measured lung function in a cohort of 44 children with BPD (mean gestational age 25.6 weeks and mean birth weight $0.767 \mathrm{~kg}$ ) during their first 3 years of life [52]. Although lung volumes increased with time, persistent flow limitation was evidenced. At 6,12 and 24 months, low partial expiratory airflow, measured by maximum flow at functional residual capacity (VmaxFRC), was shown, without any significant increase over time.

Compromised pulmonary function has also been demonstrated in older children, although evaluation of the role of BPD in conditioning alterations is difficult to ascertain. A meta-analysis of 59 studies reported that percent of FEV1\% was reduced in preterm-born survivors, even when they did not develop BPD [53]. However, Hacking et al. compared respiratory function at 8 years in 201 extremely low birth weight (ELBW)/EPT and 199 randomly selected normal birth weight/full term controls [54]. FEV1 and FEF25-75\% were found to be significantly lower in patients than in controls. However, within the ELBW/EPT cohort, children who had BPD in the newborn period had significant reductions in both the FEV1 ( -0.76 standard deviation [SD]) and FEF25-75\% (- 0.58 $\mathrm{SD})$, compared with those who did not have BPD.

\section{Clinical problems \\ Hospital re-admission}

BPD is a risk factor for re-hospitalization. Several studies have reported that preterm infants are re-hospitalized more frequently than term infants. However, the prevalence of re-hospitalization is even greater in those with BPD. Lamarche-Vadel et al. estimated the re-hospitalization rate of 376 patients with EPT during their first 9 months after discharge and found that $47.3 \%$ were readmitted at least once in $55 \%$ of the cases for respiratory disorders [55]. However, the re-hospitalization rate was higher for children who had had BPD (OR 2.2; 95\% CI 1.3-3.7).

Ralser et al. reported the rate of readmission of 377 children born before 32 weeks of gestational age and found that 151 of them (40.1\%) in the first and 93 of them $(24.7 \%)$ in the second year of life were hospitalized [56]. Respiratory disorders accounted for 42.1 and $47.4 \%$ of total readmissions, respectively, in the first and second years of life. BPD was a risk condition relevant to readmission in both years of the study period. Greenough et al. conducted a study in 235 infants with a median gestational age of 27 weeks [57]. They demonstrated that, despite routine use of antenatal steroids and postnatal surfactant, patients with BPD, particularly those who received home oxygen treatment, showed high rates of re-hospitalization after discharge from the neonatal care unit (median of 2 new admissions per patient). 
Risk of respiratory tract infections and asthma-like symptoms In preterm infants with $\mathrm{BPD}$, the risk of respiratory infections is greater than in preterm infants without $B P D$, who in turn suffer from respiratory infections more frequently than term infants [58]. Infections can lead to even greater lung damage, as evidenced by several epidemiological evaluations and animal studies. Moreover, common respiratory infections can cause very severe respiratory disease leading to hospitalization in most cases. A good example in this regard was provided in the study by Groothuis et al. [59]. These authors studied morbidity due to respiratory syncytial virus (RSV) infection during an epidemic in children with BPD. RSV disease was diagnosed in $59 \%$ of old BPD patients, with $69 \%$ of them requiring hospitalization that lasted more than 7 days in approximately twothirds of cases. By contrast, hospitalization rates for normal children ranged from 1 in 50 to 1 in 500, and the usual duration of hospitalization was four to 7 days. However, modern approaches to the prevention of BPD development and the use of prophylaxis against RSV have significantly reduced the clinical problems due to this virus in children with new BPD. A recent evaluation of RSV hospitalization rates in the USA between 1998 and 2008 revealed that, in the 11-year period, the predicted rate of RSV hospitalization statistically significantly decreased by $48 \%$ (from 93.78 to 49.06 per 1 million children; $\mathrm{p}=0.013$ ).

Regarding asthma-like signs and symptoms, it has been reported that children with EPT at 11 years of age suffered from clinically evident asthma in $25 \%$ of cases and had abnormal spirometry in more than $50 \%$. However, despite similar clinical features, allergic asthma and asthma following BPD are different. Patients with allergic asthma have an increased prevalence of atopy, eosinophilic inflammation and high levels of exhaled nitric oxide. Children with BPD have neutrophilic airway inflammation and lower values of exhaled nitric oxide and exhaled breath temperature [60]. The airway obstruction is only partially reversed by beta2-agonists, the response to inhaled corticosteroids is poorer, and the acute exacerbations are fewer because patients with BPD suffer from fixed airway narrowing, as evidenced by HRTC studies [61-63].

Children with BPD might be intolerant to exercise due to abnormal bronchial function. Karila et al. reported that children with BPD examined at 7-14 years old had ventilatory limitations on exercise, with greater use of the ventilatory reserves $(\mathrm{p}<0.01)$ and lower maximal ventilation $(\mathrm{p}<0.01)$ and tidal volume $(\mathrm{p}=0.01)$ [64]. Moreover, changes in ventilation $(\mathrm{p}<0.0001)$ and tidal volume $(p=0.003)$ during exercise were significantly smaller in the BPD group than in controls.

\section{Lung arterial hypertension}

The lung vascular abnormalities that accompany BPD can lead to pulmonary arterial hypertension. In a recent metaanalysis regarding studies published from January 2000 to December 2015 it was reported that this complication occurs in 17\% (95\% CI 12-21) of BPD cases, regardless of severity of disease. However, it seems significantly more common in moderate-severe BPD (24\%; 95\% CI 17-30) [65]. Early diagnosis is essential for optimal management and for improving final outcome of these patients. Although cardiac catheterization remains the gold standard for the diagnosis of pulmonary hypertension in infants, transthoracic echocardiography is the most commonly used screening tool for this purpose because it is a noninvasive techniques and permits a readily available assessment of heart function. A retrospective review [66] of data from 25 children $<2$ years of age with a diagnosis of BPD revealed that, compared with cardiac catheterization, measurements of systolic pulmonary artery pressure with echocardiography diagnosed correctly the presence or absence of pulmonary hypertension in $79 \%$ of the cases. However, severity was assessed correctly in only $47 \%$ of the children. Cardiac CT and magnetic resonance can offer details of right ventricle and pulmonary vasculature characteristics, further improving correct diagnosis of pulmonary hypertension [67]. Management is mainly directed to reduce hypertension with vasodilators. Oral sildenafil is the drug of choice. Prostacyclin analogues such as epoprostenol, given by inhalation or intravenously, and endothelin antagonists, such as oral bosentan, have been studied in a limited number of infants showing promising results. Finally, intravenous milrinone, a phosphodiesterase III inhibitor, is a possible alternative, especially in children that have poor response to previously reported drugs. However, as hypoxemia and hypercarbia and poor nutrition status are strictly related to progression of pulmonary hypertension, hypoxemic episodes have to be avoided or immediately treated and adequate nutritional support has to be assured [67]. Finally, use of nitric oxide is debated. However, administration of this gas has been suggested in preterm infants with premature or prolonged rupture of membranes, oligohydramnios and pulmonary hypoplasia as in these patients undetectable nitrite/nitrate levels in airway samples have been reported and this might indicate a reduced nitric oxide production playing a role in the pathogenesis of hypoxic respiratory failure and BPD $[68,69]$.

\section{Prevention and treatment of bronchopulmonary dysplasia (BPD)}

Prenatal prevention

Because the most severe cases of BPD occur in EPT and VPT, prevention of premature birth remains the 
most effective measure to reduce the risk of BPD. Use of maternal progesterone supplementation, surgical closure of the cervix with cerclage, prevention of the exposure of pregnant women to cigarette smoke, avoidance of fertility treatments when several follicles are potentially available for ovulation in order to reduce the risk of multiple pregnancies and dedicated preterm birth prevention clinics are well known measures to prevent premature births [70]. Moreover, in women at risk for premature delivery, administration of glucocorticosteroids (GCS; betamethasone, dexamethasone, or hydrocortisone) is essential to improve foetal lung maturation. In a recent Cochrane review including 30 studies of 7774 women and 8158 infants, it was reported that antenatal corticosteroids compared to placebo or no treatment reduced several problems strictly correlated with prematurity, including RDS, particularly more severe cases (average relative risk of moderate/severe RDS 0.59, 95\% CI 0.38-0.91 [71]. Less important, although present, was the advantage found in the prevention of chronic lung diseases (average relative risk [RR] 0.86; 95\% CI 0.42-1.79).

\section{Postnatal prevention and treatment Ventilation}

In ventilated preterm infants, permissive hypercapnia with a partial pressure of $\mathrm{CO}_{2}$ in the arterial blood $\left(\mathrm{PaCO}_{2}\right)$ between 45 and $55 \mathrm{mmHg}$ and a $\mathrm{pH}>7.20$ has been suggested to avoid high tidal volumes and lung overinflation. However, the effects on BPD development are modest if any [72]. By contrast, an attempt to use higher $\mathrm{PaCO}_{2}$ values had no positive effect [73].

It is recommended to reduce intubation as much as possible. To avoid the risk of aggressive mechanical ventilation, non-invasive respiratory ventilation strategies have been adopted, including the use of non-invasive positive pressure ventilation (NIPPV), nasal continuous positive airway pressure (NCPAP) and high flow nasal cannulas (HFNCs). A meta-analysis of 7 studies comparing ventilation strategies with or without an endotracheal tube in infants $<30$ weeks of gestational age showed that avoiding the use of a tube had a small but significant beneficial impact in preventing BPD (OR 0.83; 95\% CI 0.71-096) [74], indicating that these strategies should be systematically used in EPT and VPT. However, the best non-invasive method to decrease the development of BPD has not defined. Kugelman et al. reported that infants treated with NIPPV compared with those with NCPAP had reduced requirements for endotracheal ventilation and a lower incidence of BPD ( $2 \%$ vs $17 \%, \mathrm{p}<0.05$, in the total cohort and $5 \%$ vs $33 \%$ in those $<1500 \mathrm{~g}, \mathrm{p}<0.05$ ) [75]. However, a meta-analysis of 10 trials enrolling a total of 1061 infants in whom early use of NIPPV and NCPAP was compared showed that, although infants with NIPPV had a reduced risk of respiratory failure and less need for intubation, no significant differences between methods in the reduction of BPD were demonstrated [76]. Similar conclusions were reported in another meta-analysis in which the two ventilation strategies were compared after extubation [77].

\section{Oxygen supplementation}

The potential correlation between supraphysiological oxygen concentrations and BPD development has led to the recommendation of accurate control of oxygen administration in preterm infants. Pulse oximetry has been used to evaluate the oxygen saturation $\left(\mathrm{SpO}_{2}\right)$ associated with the lowest risk of clinical problems in preterm infants. However, although the problem has been studied in several clinical trials, the optimal $\mathrm{SpO}_{2}$ for EPT and VPT has not been precisely defined. A recent evaluation of five randomized, controlled trials including more than 4800 infants, in whom lower (85-89\%) versus higher (91-95\%) $\mathrm{SpO}_{2}$ targets were compared, concluded that the lower target range did not reduce $\mathrm{BPD}$, severe visual problems or rate of disability at 12-24 months. By contrast, it was associated with increased risks of death and necrotizing enterocolitis [78]. However, the quality of the available data is debated, and further studies are required to draw definitive conclusions. Some authors have indicated that, in the first few minutes of life, $\mathrm{SpO}_{2}$ of $70-80 \%$ might be acceptable. However, after $5 \mathrm{~min}, \mathrm{SpO}_{2}$ must be maintained at between 88 and $92 \%$ with a higher alarm limit of $96 \%$. Slightly higher $\mathrm{SpO}_{2}$ can be tolerated for MPT patients for whom the alarm limit of $97-98 \%$ can be accepted [79].

\section{Fluid intake and nutrition}

High fluid intake during the first week of life and lack of appropriate postnatal weight loss were associated in preterm infants with an increased risk of BPD development because of pulmonary congestion and oedema [80]. The same finding seems true for excess sodium intake, although in this case the difference between high and low sodium intake was not statistically significant [81]. To address the problem, EPT and VPT patients are often fluid restricted and receive no more than $120 \mathrm{~mL} / \mathrm{kg} /$ day. In some cases, diuretics are added, although there is no convincing evidence of the importance of these drugs in the prevention and treatment of BPD [82]. Fluid restriction can cause problems for calorie intake that must be rapidly resolved because poor nutrition favours BPD development. It must be borne in mind that preterm infants that develop BPD have increased caloric requirements because of the increased work of breathing and because of the need to aid lung healing and growth. Feedings should achieve an intake of 150 calories/kg/day, including protein at $3.5-4 \mathrm{~g} / \mathrm{kg} /$ day [83]. 


\section{Surfactant}

As previously reported, surfactant administration was one of the most important measurements capable of reducing preterm infant mortality and modifying characteristics of BPD. Early surfactant administration permitted immediate extubation to less aggressive ventilator measures, thus reducing the risk of BPD development [84]. Initially, surfactant administration was strictly associated with intubation and mechanical ventilation. When it was demonstrated that NIPPV and NCPAP were effective measures to treat RDS, non-conventional methods for surfactant administration were studied. Intratracheal catheters in infants in non-invasive ventilation were largely used and several studies have clearly evidenced that the efficacy of this procedure was even higher than that of the conventional administration of surfactant. A recent systematic review and meta-analysis [85] of the studies that have compared less and more invasive surfactant therapies has shown that the non-invasive surfactant instillation through a thin tracheal catheter in spontaneously breathing infants is significantly more effective in decreasing the risks of $\mathrm{BPD}$, of death or BPD, and of NIPPV and NCPAP failure than the strategies where surfactant is administered through an endotracheal tube. Presently, surfactants purified from animal lungs, in some cases modified by the addition of specific lipids are used. These preparations are expensive to produce and supplies are limited and this explains why several attempts to produce synthetic surfactants have been made. However, due to the complex molecular structure of natural surfactants, research was not immediately effective. However, animal studies have shown that synthetic surfactants containing surfactant protein B and $\mathrm{C}$ analogs and a phospholipid mixture can stabilize the alveoli, measured as lung gas volumes at end expiration, even if no positive end-expiratory pressure is applied [86]. The effect on lung gas volumes seems to depend on the structure of the peptides as well as the phospholipid composition. It seems that synthetic surfactants containing two peptides and a more complex phospholipid composition could be able to replace natural surfactants within the near future, but more experiments need to be performed before any conclusion can be drawn about the ideal composition of this new generation of synthetic surfactants [86].

\section{Glucocorticosteroids (GCS)}

Some years ago, it was shown that GCS administration within the first 2 weeks of life to ventilated preterm infants could reduce the risk of BPD development and favour early extubation $[87,88]$. Later, administration, at $>3$ weeks after birth, was no more effective in BPD, although it could still facilitate earlier extubation $[87,88]$.
However, despite these benefits, routine use of postnatal GCS in the first days of life in children with EPT and VPT remains debated because it was found to be associated with a number of severe adverse events, including hyperglycaemia, hypertension, hypertrophic cardiomyopathy, severe retinopathy of prematurity and, mainly, cerebral palsy $[87,88]$.

Recently, it was suggested that, because BPD is per se associated with an increased risk of neurodevelopmental problems, a course of postnatal GCS might be of benefit in children with the highest risk of BPD [89]. Low dose hydrocortisone $(1 \mathrm{mg} / \mathrm{kg}$ of hydrocortisone hemisuccinate per day divided into two doses for 7 days, followed by one dose of $0.5 \mathrm{mg} / \mathrm{kg} /$ day for 3 days) administered to children $<28$ weeks of gestation, seems effective in reducing BPD without any adverse impact on neurodevelopmental outcomes [89]. Baud et al. reported that the survival rate without BPD at 36 weeks was higher in preterm infants receiving early hydrocortisone than in those not administered it (60\% vs $51 \%$; OR $1.48,95 \%$ CI $1.02-2.16, \mathrm{p}=0.04$ ) [90], although treatment had no effect on neurodevelopment [91]. Positive results were also obtained with low-dose dexamethasone $(<0.2 \mathrm{mg} /$ $\mathrm{kg} /$ day), which is currently recommended for babies who remain ventilator dependent after 1-2 weeks [92]. A trial to evaluate whether even lower doses of dexamethasone (13 doses of $0.015 \mathrm{~mL} / \mathrm{kg} /$ day in the first 16 days of life) is ongoing [93]. To reduce the risk of systemic GCS, inhaled GCS has been suggested and used in several trials. A recent meta-analysis of published trials concluded that inhaled steroids (beclomethasone, budesonide, fluticasone, flunisolide, and dexamethasone) were associated with a significant reduction in BPD development at 36 weeks of postmenstrual age $(R R=0.77,95 \%$ CI 0.65-0.91) [94]. This finding seems to suggest that inhaled steroids are an obvious logical alternative to systemic steroids to prevent BPD. However, in the study by Bassler et al. a trend towards increased mortality in children receiving budesonide was shown [95]. Moreover, long-term effects on neurological development were not clearly established, indicating that, as for systemic steroids, further studies are needed to establish the doses and time of administration for inhaled steroids, together with the real risk of severe adverse events.

\section{Caffeine}

Caffeine is a methylxanthine derivative commonly used for the therapy of apnoea in preterm infants. The Caffeine for Apnea of Prematurity study showed that caffeine administration was associated with a significant reduction in BPD development and reduced neurodisability at 18 months of age $[96,97]$. Recently, a number of cohort 
studies have further supported a role for caffeine in BPD prevention. Administration within the first 2 days of life seems to lead to a reduced risk of BPD compared to later administration (OR 0.69; 95\% CI 0.58-0.82; p < 0.001), although it was found to be associated with an increased risk of necrotizing enterocolitis (OR 1.41; 95\% CI 1.041.91; $\mathrm{p}=0.027$ ) [98-100]. The standard dose of caffeine citrate is $20 \mathrm{mg} / \mathrm{kg}$ for loading and $5-10 \mathrm{mg} / \mathrm{kg}$ for daily maintenance. The mechanism of action is unknown. However, it has been suggested that, considering its antiinflammatory properties [101], it could play a role in reducing the pathogenic mechanisms of BPD development. However, it cannot be excluded that the positive effects might derive from the reduced need for assisted ventilation.

\section{Vitamin A}

Vitamin A is essential for normal development and the integrity of the respiratory tract. Because preterm infants have low vitamin A concentrations at birth, it was theorized that systematic supplementation of vitamin A might reduce the risk of BPD development. A recent meta-analysis of the studies published through May 2016 reported that, compared to children receiving placebo, children with EPT and VPT treated with vitamin A had a lower risk of BPD, defined as the need for oxygen supplementation at 36 weeks of gestational age [102]. However, although statistically significant, a reduction was observed only in children weighing $<1000 \mathrm{~g}$ and was small. Moreover, vitamin A does not reduce the mortality and duration of mechanical ventilation or length of hospital stay, and it does not improve neurodevelopmental outcomes at 18-22 months of age. Finally, the best route of supplementation is not definitively established, although the one trial that gave enteral vitamin A found no significant benefit for supplementation [103]. Consequently, it was suggested that the administration of vitamin A to preterm infants be balanced, considering advantages and problems. Administration is painful, must be repeated several times (i.e., $5000 \mathrm{U}$ i.m. 3 times/ week for a total of 12 doses) and has been associated with an increased risk of sepsis [104].

\section{Nitric oxide}

Inhaled nitric oxide has been found to be effective in the treatment of term neonates with acute hypoxaemic respiratory failure and persistent pulmonary hypertension [105]. However, the use of inhaled nitric oxide to prevent BPD development in preterm infants was not successful. A meta-analysis of the studies of this topic published through January 2016 found no advantages, either when the gas was administered early after birth or when it was administered later [106], which explains why routine use of nitric oxide is not recommended by experts and scientific societies $[107,108]$. However, addition of vitamin A to nitric oxide administration can significantly improve final effect of nitric oxide inhalation [109]. Gadhia et al. [109] reported that the association of inhaled nitric oxide and intramuscular vitamin A reduced the incidence of BPD and BPD plus death in preterm infants weighing 750-999 $\mathrm{g}$ and improved neurocognitive outcomes at 1 years in those in the 500-749 birth weight group.

\section{Cell therapy}

There is evidence that stem and progenitor cell impairment can favour BPD development [110]. Based on this finding, it has been supposed that the use of exogenous stem or progenitor cells could protect or regenerate even a damaged lung.

A great number of animal studies have used lung-resident mesenchymal stem or progenitor cells (MSCs) in BPD models $[111,112]$. Although MSCs precise role in organ function remains incompletely defined, mounting evidence suggested that they are an important component of the parenchymal progenitor cell niche and orchestrate organ homeostasis and repair following injury [111]. Different cell types-either intact cells or their conditioned medium-were administered, but bone marrow and umbilical cord blood derived mesenchymal stem cells were most prevalent. Available studies reported positive effects on outcome parameters including alveolar and vascular morphometry, lung function, and inflammation [112]. Cell homing to the lungs was demonstrated in some studies, but the therapeutic effects seemed to be mostly mediated via paracrine modulation of inflammation, fibrosis and angiogenesis. Positive results with increased vessel density, reduced pulmonary artery pressure and increased alveolar wall thickness were also obtained when MSCs derived from the bone marrow of healthy adult rodents were administered intravenously [113] or intratracheally [12]. Starting with these and other similar experimental results [114], attempts to evaluate cell therapy in humans have been undertaken. MSCs were found to be safe and well tolerated in adult patients [115-118]. No evidence of pro-fibrotic and tumorigenic potential of MSCs was reported. Moreover, in one study carried out in patients with chronic obstructive pulmonary disease and an elevated $\mathrm{C}$ reactive protein at baseline, it was demonstrated that MSC administration was followed by a significant reduction of the inflammatory marker [117].

The results of MSC administration in preterm infants were promising. Chang et al. assessed the safety and feasibility of a single, intratracheal transplant of human umbilical cord blood-derived MSCs in preterm infants 
with a mean gestational age of $25.3 \pm 0.9$ weeks old with high risk BPD [119]. Administration of both low and high doses of cells was well tolerated, whereas the concentration of pro-inflammatory cytokines in tracheal aspirates was significantly reduced after 7 days. Respiratory severity score measured in the 3 weeks after transplantation was significantly lower than in comparable historical controls [119]. Other studies are ongoing or have been completed (NCT02381366, NCT02443961, NCT01828957). Results have not yet been published. However, preliminary reports of the first of them [120] suggest that MSCs were generally well tolerated with no early deaths or cardiorespiratory problems. However, a study patient died about 4 months later as a result of pulmonary hypertension and lung hypoplasia [121]. All these findings clearly indicate that cell therapy could be an attractive measure for the future. However, further studies are needed to evaluate the role of MSCs in the pathogenesis and treatment of BPD. Which MCs have to be selected, the dose and duration of administration are not defined as the risk of adverse events following administration. Finally, large-scale production of MSCs for transplant is for the moment a very difficult problem to solve.

\section{Conclusions}

$\mathrm{BPD}$ is a respiratory condition that presently occurs in EPT and VPT and can lead to chronic respiratory problems. Although knowledge about BPD pathogenesis has significantly increased in recent years, not all of the mechanisms that lead to lung damage are completely understood, which explains why therapeutic approaches that are theoretically effective have been only partly satisfactory or useless and, in some cases, potentially negative. However, prevention of prematurity, systematic use of nonaggressive ventilator measures, avoiding supraphysiologic oxygen exposure and administration of surfactant, caffeine and vitamin A can significantly reduce the risk of BPD development. Cell therapy is the most fascinating new measure to address the lung damage due to BPD. It is desirable that ongoing studies yield positive results to definitively solve a major clinical, social and economic problem.

\footnotetext{
Abbreviations

BPD: bronchopulmonary dysplasia; Cl: confidence interval; CT: computed tomography; DALY: disability-adjusted life year; ELBW: extremely low birth weight infants; EPT: extremely preterm; FVC: forced vital capacity; FEV1: forced expiratory volume in $1 \mathrm{~s}$; FEF25\%-75\%: forced expiratory flow between 25 and $75 \%$ of vital capacity; GCS: glucocorticoids; HFNCs: high flow nasal cannulas; HRCT: high-resolution computed tomography; IL: interleukin; MPT: modestly preterm infants; MSCs: mesenchymal stem or progenitor cells; OR: odds ratio; NCPAP: nasal continuous positive airway pressure; NIPPV: non-invasive positive pressure ventilation; $\mathrm{PaCO}_{2}$ : partial pressure of $\mathrm{CO}_{2}$ in the arterial blood; $\mathrm{ROS}$ :
}

reactive oxygen species; RR: relative risk; RSV: respiratory syncytial virus; $S D$ : standard deviation; Th2: T-helper 2; VPT: very preterm infants.

\section{Authors' contributions}

NP wrote the first draft of the manuscript; GMDP participated in the literature collection and evaluation; ST gave a scientific contribution; SE supervised and critically revised the manuscript. All authors read and approved the final manuscript.

\section{Author details \\ ${ }^{1}$ Università degli Studi di Milano, Milan, Italy. ${ }^{2}$ Pediatric Clinic, Department of Surgical and Biomedical Sciences, Università degli Studi di Perugia, Piazza Menghini 1,06129 Perugia, Italy.}

\section{Acknowledgements}

Not applicable.

\section{Competing interests}

The authors declare that they have no competing interests.

\section{Availability of data and materials}

Data and materials used are included in the review.

\section{Consent for publication}

Not applicable.

\section{Ethics approval and consent to participate}

All the studies mentioned in this review have been approved by the Ethics Committee and written informed consent has been obtained by all the participants.

\section{Funding}

This review was supported by an unrestricted grant from the World Association for Infectious Diseases and Immunological Disorders (WAidid) and the Italian Ministry of Health (Fondazione IRCCS Ca' Granda Ospedale Maggiore Policlinico 2018 850/02).

\section{Publisher's Note}

Springer Nature remains neutral with regard to jurisdictional claims in published maps and institutional affiliations.

Received: 8 September 2017 Accepted: 16 February 2018

Published online: 20 February 2018

\section{References}

1. Blencowe H, Cousens S, Oestergaard MZ, Chou D, Moller AB, Narwal R, Adler A, Vera Garcia C, Rohde S, Say L, Lawn JE. National, regional, and worldwide estimates of preterm birth rates in the year 2010 with time trends since 1990 for selected countries: a systematic analysis and implications. Lancet. 2012;379:2162-72.

2. Natarajan G, Shankaran S. Short- and long-term outcomes of moderate and late preterm infants. Am J Perinatol. 2016;33:305-17.

3. Kotecha SJ, Dunstan FD, Kotecha S. Long term respiratory outcomes of late preterm-born infants. Semin Fetal Neonatal Med. 2012;17:77-81.

4. Kair LR, Leonard DT, Anderson JM. Bronchopulmonary dysplasia. Pediatr Rev. 2012;33:255-6.

5. Bhandari A, Bhandari V. Pitfalls, problems, and progress in bronchopulmonary dysplasia. Pediatrics. 2009;123:1562-73.

6. Northway WH Jr, Rosan RC, Porter DY. Pulmonary disease following respirator therapy of hyaline-membrane disease. Bronchopulmonary dysplasia. N Engl J Med. 1967;276:357-68.

7. Abman SH, Bancalari E, Jobe A. The evolution of bronchopulmonary dysplasia after 50 years. Am J Respir Crit Care Med. 2017;195:421-4.

8. Baraldi E, Filippone M. Chronic lung disease after premature birth. N Engl J Med. 2007;357:1946-55.

9. Amata E, Pittalà V, Arena E, Marrazzo A, Parenti C, Prezzavento O, Nabavi $\mathrm{SM}$, Salerno L. Role of the Nrf2/HO-1 axis in bronchopulmonary dysplasia and hyperoxic lung injuries. Clin Sci. 2017;131:1701-12. 
10. Dennery PA. Heme oxygenase in neonatal lung injury and repair. Antioxid Redox Signal. 2014;21:1881-92.

11. Jobe AH. Mechanisms of lung injury and bronchopulmonary dysplasia. Am J Perinatol. 2016;33:1076-8.

12. Aslam M, Baveja R, Liang OD, Fernandez-Gonzalez A, Lee C, Mitsialis SA, Kourembanas $S$. Bone marrow stromal cells attenuate lung injury in a murine model of neonatal chronic lung disease. Am J Respir Crit Care Med. 2009;180:1122-30.

13. Auten RL, Mason SN, Auten KM, Brahmajothi M. Hyperoxia impairs postnatal alveolar epithelial development via NADPH oxidase in newborn mice. Am J Physiol Lung Cell Mol Physiol. 2009;297:L134-42.

14. Balasubramaniam V, Mervis CF, Maxey AM, Markham NE, Abman SH. Hyperoxia reduces bone marrow, circulating, and lung endothelial progenitor cells in the developing lung: implications for the pathogenesis of bronchopulmonary dysplasia. Am J Physiol Lung Cell Mol Physiol. 2007;292:L1073-84.

15. Tanswell AK, Freeman BA. Pulmonary antioxidant enzyme maturation in the fetal and neonatal rat. I. Developmental profiles. Pediatr Res. 1984;18:584-7.

16. Kobr J, Kuntscher V, Molacek J, Hes O, Pizingerova K, Kocova J, Topolcan O. Diffuse alveolar damage due to inappropriate strategy of mechanical ventilation in an experimental porcine model. In Vivo. 2010;24:699-704.

17. Coalson JJ. Pathology of new bronchopulmonary dysplasia. Semin Neonatol. 2003;8:73-81.

18. Morrow LA, Wagner BD, Ingram DA, Poindexter BB, Schibler K, Cotten CM, Dagle J, Sontag MK, Mourani PM, Abman SH. Antenatal determinants of bronchopulmonary dysplasia and late respiratory disease in preterm infants. Am J Respir Crit Care Med. 2017. https://doi. org/10.1164/rccm.201612-2414oc (Epub Mar 1).

19. Lapcharoensap W, Kan P, Powers RJ, Shaw GM, Stevenson DK, Gould $J B$, Wirtschafter DD, Lee HC. The relationship of nosocomial infection reduction to changes in neonatal intensive care unit rates of bronchopulmonary dysplasia. J Pediatr. 2017;180:105-9.

20. Ballard AR, Mallett LH, Pruszynski JE, Cantey JB. Chorioamnionitis and subsequent bronchopulmonary dysplasia in very-low-birth weight infants: a 25-year cohort. J Perinatol. 2016;36:1045-8.

21. Hartling L, Liang Y, Lacaze-Masmonteil T. Chorioamnionitis as a risk factor for bronchopulmonary dysplasia: a systematic review and metaanalysis. Arch Dis Child Fetal Neonatal Ed. 2012;97:F8-17.

22. Metcalfe A, Lisonkova S, Sabr Y, Stritzke A, Joseph KS. Neonatal respiratory morbidity following exposure to chorioamnionitis. BMC Pediatr. 2017;17:128.

23. Eriksson L, Haglund B, Odlind V, Altman M, Ewald U, Kieler H. Perinatal conditions related to growth restriction and inflammation are associated with an increased risk of bronchopulmonary dysplasia. Acta Paediatr. 2015;104:259-63.

24. Poindexter BB, Martin CR. Impact of nutrition on bronchopulmonary dysplasia. Clin Perinatol. 2015;42:797-806.

25. Bhandari V, Bizzarro MJ, Shetty A, Zhong X, Page GP, Zhang H, Ment LR, Gruen JR, Neonatal Genetics Study Group. Familial and genetic susceptibility to major neonatal morbidities in preterm twins. Pediatrics. 2006;117:1901-6.

26. Hadchouel A, Durrmeyer X, Bouzigon E, Incitti R, Huusko J, Jarreau PH, Lenclen R, Demenais F, Franco-Montoya ML, Layouni I, Patkai J, Bourbon J, Hallman M, Danan C, Delacourt C. Identification of SPOCK2 as a susceptibility gene for bronchopulmonary dysplasia. Am J Respir Crit Care Med. 2011;184:1164-70

27. Wang H, St Julien KR, Stevenson DK, Hoffmann TJ, Witte JS, Lazzeroni LC, Krasnow MA, Quaintance CC, Oehlert JW, Jelliffe-Pawlowski LL, Gould JB, Shaw GM, O'Brodovich HM. A genome-wide association study (GWAS) for bronchopulmonary dysplasia. Pediatrics. 2013;132:290-7.

28. Kwinta P, Pietrzyk JJ. Preterm birth and respiratory disease in later life. Expert Rev Respir Med. 2010;4:593-604.

29. Klinger G, Sokolover N, Boyko V, Sirota L, Lerner-Geva L, Reichman B. Perinatal risk factors for bronchopulmonary dysplasia in a national cohort of very-low-birthweightinfants. Am J Obstet Gynecol. 2013;208:115.e1-9.

30. Patel RM. Short- and long-term outcomes for extremely preterm infants. Am J Perinatol. 2016;33:318-28.

31. Howling SJ, Northway WH Jr, Hansell DM, Moss RB, Ward S, Müller NL. Pulmonary sequelae of bronchopulmonary dysplasia survivors: high-resolution CT findings. AJR Am J Roentgenol. 2000;174:1323-6.

32. Shennan AT, Dunn MS, Ohlsson A, Lennox K, Hoskins EM. Abnormal pulmonary outcomes in premature infants: prediction from oxygen requirement in the neonatal period. Pediatrics. 1988;82:527-32.

33. Ryan RM. A new look at bronchopulmonary dysplasia classification. J Perinatol. 2006;26:207-9.

34. Day CL, Ryan RM. Bronchopulmonary dysplasia: new becomes old again! Pediatr Res. 2017:81:210-3.

35. Maniscalco WM, Watkins RH, D'Angio CT, Ryan RM. Hyperoxic injury decreases alveolar epithelial cell expression of vascular endothelial growth factor (VEGF) in neonatal rabbit lung. Am J Respir Cell Mol Biol. 1997;16:557-67.

36. Bhandari V, Choo-Wing R, Lee CG, Zhu Z, Nedrelow JH, Chupp GL, Zhang X, Matthay MA, Ware LB, Homer RJ, Lee PJ, Geick A, de Fougerolles AR, Elias JA. Hyperoxia causes angiopoietin 2-mediated acute lung injury and necrotic cell death. Nat Med. 2006;12:1286-93.

37. Thomas W, Seidenspinner S, Kramer BW, Wirbelauer J, Kawczyńska-Leda N, Szymankiewicz M, Speer CP. Airway angiopoietin-2 in ventilated very preterm infants: association with prenatal factors and neonatal outcome. Pediatr Pulmonol. 2011;46:777-84.

38. De Paepe ME, Patel C, Tsai A, Gundavarapu S, Mao Q. Endoglin (CD105) up-regulation in pulmonary microvasculature of ventilated preterm infants. Am J Respir Crit Care Med. 2008;178:180-7.

39. Harijith A, Choo-Wing R, Cataltepe S, Yasumatsu R, Aghai ZH, Janér J, Andersson S, Homer RJ, Bhandari V. A role for matrix metalloproteinase 9 in IFNy-mediated injury in developing lungs: relevance to bronchopulmonary dysplasia. Am J Respir Cell Mol Biol. 2011;44:621-30.

40. Van Marter LJ. Epidemiology of bronchopulmonary dysplasia. Semin Fetal Neonatal Med. 2009;14:358-66.

41. Gortner L, Misselwitz B, Milligan D, Zeitlin J, Kollee L, Boerch K, Agostino R, Van Reempts P, Chabernaud JL, Bréart G, Papiernik E, Jarreau $\mathrm{PH}$, Carrapato M, Gadzinowski J, Draper E, Members of the MOSAIC Research Group. Rates of bronchopulmonary dysplasia in very preterm neonates in Europe: results from the MOSAIC cohort. Neonatology. 2011;99:112-7.

42. Aukland SM, Rosendahl K, Owens CM, Fosse KR, Eide GE, Halvorsen T. Neonatal bronchopulmonary dysplasia predicts abnormal pulmonary HRCT scans in long-term survivors of extreme preterm birth. Thorax. 2009;64:405-10.

43. Wong PM, Lees AN, Louw J, Lee FY, French N, Gain K, Murray CP, Wilson $A$, Chambers DC. Emphysema in young adult survivors of moderate-tosevere bronchopulmonary dysplasia. Eur Respir J. 2008;32:321-8.

44. Aquino SL, Schechter MS, Chiles C, Ablin DS, Chipps B, Webb WR. Highresolution inspiratory and expiratory $C T$ in older children and adults with bronchopulmonary dysplasia. Am J Roentgenol. 1999;173:963-7.

45. Oppenheim C, Mamou-Mani T, Sayegh N, de Blic J, Scheinmann P, Lallemand D. Bronchopulmonary dysplasia: value of CT in identifying pulmonary sequelae. Am J Roentgenol. 1994;163:169-72.

46. Mahut B, De Blic J, Emond S, Benoist MR, Jarreau PH, Lacaze-Masmonteil T, et al. Chest computed tomography findings in bronchopulmonary dysplasia and correlation with lung function. Arch Dis Child Fetal Neonatal Ed. 2007:92:F459-64.

47. Hakulinen AL, Heinonen $\mathrm{K}$, Länsimies E, Kiekara O. Pulmonary function and respiratory morbidity in school-age children born prematurely and ventilated for neonatal respiratory insufficiency. Pediatr Pulmonol. 1990;8:226-32.

48. Northway WH Jr, Moss RB, Carlisle KB, Parker BR, Popp RL, Pitlick PT, Eichler I, Lamm RL, Brown BW Jr. Late pulmonary sequelae of bronchopulmonary dysplasia. N Engl J Med. 1990;323:1793-9.

49. Islam JY, Keller RL, Aschner JL, Hartert TV, Moore PE. Understanding the short- and long-term respiratory outcomes of prematurity and bronchopulmonary dysplasia. Am J Respir Crit Care Med. 2015;192:134-56.

50. Baraldi E, Filippone M, Trevisanuto D, Zanardo V, Zacchello F. Pulmonary function until two years of life in infants with bronchopulmonary dysplasia. Am J Respir Crit Care Med. 1997;155:149-55.

51. Robin B, Kim YJ, Huth J, Klocksieben J, Torres M, Tepper RS, Castile RG, Solway J, Hershenson MB, Goldstein-Filbrun A. Pulmonary function in bronchopulmonary dysplasia. Pediatr Pulmonol. 2004;37:236-42. 
52. Fakhoury KF, Sellers C, Smith EO, Rama JA, Fan LL. Serial measurements of lung function in a cohort of young children with bronchopulmonary dysplasia. Pediatrics. 2010;125:e1441-7.

53. Kotecha SJ, Edwards MO, Watkins WJ, Henderson AJ, Paranjothy S, Dunstan FD, Kotecha S. Effect of preterm birth on later FEV1: a systematic review and meta-analysis. Thorax. 2013;68:760-6.

54. Hacking DF, Gibson AM, Robertson C, Doyle LW. Respiratory function at age 8-9 after extremely low birthweight or preterm birth in Victoria in 1997. Pediatr Pulmonol. 2013:48:449-55.

55. Lamarche-Vadel A, Blondel B, Truffer P, Burguet A, Cambonie G, Selton D, Arnaud C, Lardennois C, du Mazaubrun C, N'Guyen S, Mathis J, Bréart G, Kaminski M, EPIPAGE Study Group. Re-hospitalization in infants younger than 29 weeks' gestation in the EPIPAGE cohort. Acta Paediatr. 2004;93:1340-5.

56. Ralser E, Mueller W, Haberland C, Fink FM, Gutenberger KH, Strobl R, Kiechl-Kohlendorfer U. Rehospitalization in the first 2 years of life in children born preterm. Acta Paediatr. 2012;101:e1-5.

57. Greenough A, Alexander J, Burgess S, Chetcuti PA, Cox S, Lenney W, Turnbull F, Shaw NJ, Woods A, Boorman J, Coles S, Turner J. Home oxygen status and rehospitalisation and primary care requirements of infants with chronic lung disease. Arch Dis Child. 2002;86:40-3.

58. Garcia-Garcia ML, Gonzalez-Carrasco E, Quevedo S, Munoz C, SanchezEscudero V, Pozo F, Casas I, Calvo C. Clinical and virologic characteristics of early and moderate preterm infants readmitted with viral respiratory infections. Pediatr Infect Dis J. 2015;34:693-9.

59. Groothuis JR, Gutierrez KM, Lauer BA. Respiratory syncytial virus infection in children with bronchopulmonary dysplasia. Pediatrics. 1988;82:199-203.

60. El Mazloum D, Moschino L, Bozzetto S, Baraldi E. Chronic lung disease of prematurity: long-term respiratory outcome. Neonatology. 2014:105:352-6.

61. Baraldi E, Bonetto G, Zacchello F, Filippone M. Low exhaled nitric oxide in school-age children with bronchopulmonary dysplasia and airflow limitation. Am J Respir Crit Care Med. 2005;171:68-72

62. Halvorsen T, Skadberg BT, Eide GE, Røksund O, Aksnes L, Øymar K. Characteristics of asthma and airway hyper-responsiveness after premature birth. Pediatr Allergy Immunol. 2005;16:487-94.

63. Qu Y, Cao Y, Liao M, Lu Z. Sagittal-lung CT measurements in the evaluation of asthma-COPD overlap syndrome: a distinctive phenotype from COPD alone. Radiol Med. 2017. https://doi.org/10.1007/s11547-0170743-9 (Epub Mar 3).

64. Karila C, Saulnier JP, Elie C, Taupin P, Scheinmann P, Le Bourgeois $M$, Waernessycle $S$, de Blic J. Exercise alveolar hypoventilation in long-term survivors of bronchopulmonary dysplasia. Rev Mal Respir. 2008;25:303-12.

65. An HS, Bae EJ, Kim GB, Kwon BS, Beak JS, Kim EK, et al. Pulmonary hypertension in preterm infants with bronchopulmonary dysplasia. Korean Circ J. 2010;40:131-6.

66. Al-Ghanem G, Shah P, Thomas S, Banfield L, El Helou S, Fusch C, Mukerji A. Bronchopulmonary dysplasia and pulmonary hypertension: a metaanalysis. J Perinatol. 2017:37:414-9.

67. Mourani PM, Sontag MK, Younoszai A, IVy DD, Abman SH. Clinical utility of echocardiography for the diagnosis and management of pulmonary vascular disease in young children with chronic lung disease. Pediatrics. 2008;121:317-25.

68. Kumar VHS. Diagnostic approach to pulmonary hypertension in premature neonates. Children. 2017:4

69. Aikio O, Metsola J, Vuolteenaho R, Perhomaa M, Hallman M. Transient defect in nitric oxide generation after rupture of fetal membranes and responsiveness to inhaled nitric oxide in very preterm infants with hypoxic respiratory failure. J Pediatr. 2012;161:397-403.

70. Newnham JP, Dickinson JE, Hart RJ, Pennell CE, Arrese CA, Keelan JA. Strategies to prevent preterm birth. Front Immunol. 2014;5:584.

71. Roberts D, Brown J, Medley N, Dalziel SR. Antenatal corticosteroids for accelerating fetal lung maturation for women at risk of preterm birth. Cochrane Database Syst Rev. 2017;3:CD004454.

72. Thome UH, Ambalavanan N. Permissive hypercapnia to decrease lung injury in ventilated preterm neonates. Semin Fetal Neonatal Med. 2009;14:21-7.

73. Thome UH, Genzel-Boroviczeny O, Bohnhorst B, Schmid M, Fuchs H, Rohde O, Avenarius S, Topf HG, Zimmermann A, Faas D, Timme K,
Kleinlein B, Buxmann H, Schenk W, Segerer H, Teig N, Bläser A, Hentschel R, Heckmann M, Schlösser R, Peters J, Rossi R, Rascher W, Böttger R, Seidenberg J, Hansen G, Zernickel M, Bode H, Dreyhaupt J, Muche R, Hummler HD, PHELBI Study Group. Neurodevelopmental outcomes of extremely low birthweight infants randomised to different $\mathrm{PCO}_{2}$ targets: the PHELBI follow-up study. Arch Dis Child Fetal Neonatal Ed. 2017. https://doi.org/10.1136/archdischild-2016-311581 (Epub Jan 13)

74. Fischer HS, Bührer C. Avoiding endotracheal ventilation to prevent bronchopulmonary dysplasia: a meta-analysis. Pediatrics. 2013;132:e1351-60.

75. Kugelman A, Feferkorn I, Riskin A, Chistyakov I, Kaufman B, Bader D. Nasal intermittent mandatory ventilation versus nasal continuous positive airway pressure for respiratory distress syndrome: a randomized, controlled, prospective study. J Pediatr. 2007;150:521-6.

76. Lemyre B, Laughon M, Bose C, Davis PG. Early nasal intermittent positive pressure ventilation (NIPPV) versus early nasal continuous positive airway pressure (NCPAP) for preterm infants. Cochrane Database Syst Rev. 2016;12:CD005384.

77. Lemyre B, Davis PG, De Paoli AG, Kirpalani H. Nasal intermittent positive pressure ventilation (NIPPV) versus nasal continuous positive airway pressure (NCPAP) for preterm neonates after extubation. Cochrane Database Syst Rev. 2017;2:CD003212.

78. Stenson BJ. Oxygen saturation targets for extremely preterm infants after the NeOProM trials. Neonatology. 2016;109:352-8.

79. Nelin LD, Bhandari V. How to decrease bronchopulmonary dysplasia in your neonatal intensive care unit today and "tomorrow". F1000Res. 2017;6:539.

80. Oh W, Poindexter BB, Perritt R, Lemons JA, Bauer CR, Ehrenkranz RA, Toll BJ, Poole K, Wright LL, Neonatal Research Network. Association between fluid intake and weight loss during the first ten days of life and risk of bronchopulmonary dysplasia in extremely low birth weight infants. J Pediatr. 2005;147:786-90.

81. Hartnoll G, Bétrémieux P, Modi N. Randomised controlled trial of postnatal sodium supplementation on oxygen dependency and body weight in 25-30 week gestational age infants. Arch Dis Child Fetal Neonatal Ed. 2000;82:F19-23.

82. Stewart A, Brion LP. Intravenous or enteral loop diuretics for preterm infants with (or developing) chronic lung disease. Cochrane Database Syst Rev. 2011;9:CD001453.

83. Biniwale MA, Ehrenkranz RA. The role of nutrition in the prevention and management of bronchopulmonary dysplasia. Semin Perinatol. 2006;30:200-8.

84. Stevens TP, Harrington EW, Blennow M, Soll RF. Early surfactant administration with brief ventilation vs. selective surfactant and continued mechanical ventilation for preterm infants with or at risk for respiratory distress syndrome. Cochrane Database Syst Rev. 2007;4:CD003063.

85. Rigo V, Lefebvre C, Broux I. Surfactant instillation in spontaneously breathing preterm infants: a systematic review and meta-analysis. Eur J Pediatr. 2016;175:1933-42.

86. Curstedt T, Calkovska A, Johansson J. New generation synthetic surfactants. Neonatology. 2013:103:327-30

87. Halliday HL, Ehrenkranz RA, Doyle LW. Early ( $<8$ days) postnatal corticosteroids for preventing chronic lung disease in preterm infants. Cochrane Database Syst Rev. 2009;1:CD001146.

88. Doyle LW, Ehrenkranz RA, Halliday HL. Late (> 7 days) postnatal corticosteroids for chronic lung disease in preterm infants. Cochrane Database Syst Rev. 2014;5:CD001145.

89. Doyle LW, Halliday HL, Ehrenkranz RA, Davis PG, Sinclair JC. An update on the impact of postnatal systemic corticosteroids on mortality and cerebral palsy in preterm infants: effect modification by risk of bronchopulmonary dysplasia. J Pediatr. 2014;165:1258-60.

90. Baud O, Maury L, Lebail F, Ramful D, El Moussawi F, Nicaise C, ZupanSimunek V, Coursol A, Beuchée A, Bolot P, Andrini P, Mohamed D, Alberti C, PREMILOC Trial Study Group. Effect of early low-dose hydrocortisone on survival without bronchopulmonary dysplasia in extremely preterm infants (PREMILOC): a double-blind, placebo-controlled, multicentre, randomised trial. Lancet. 2016;387:1827-36.

91. Baud O, Trousson C, Biran V, Leroy E, Mohamed D, Alberti C, PREMILOC Trial Group. Association between early low-dose hydrocortisone therapy in extremely preterm neonates and neurodevelopmental outcomes at 2 years of age. JAMA. 2017;317:1329-37. 
92. Jefferies AL. Postnatal corticosteroids to treat or prevent chronic lung disease in preterm infants. Paediatr Child Health. 2012;17:573-4.

93. National Perinatal epidemiology Unit. Minidex trial. https://www.npeu. ox.ac.uk/minidex. Accessed 5 June 2017.

94. Shinwell ES, Portnov I, Meerpohl JJ, Karen T, Bassler D. Inhaled corticosteroids for bronchopulmonary dysplasia: a meta-analysis. Pediatrics. 2016;138.

95. Bassler D, Plavka R, Shinwell ES, Hallman M, Jarreau PH, Carnielli V, Van den Anker JN, Meisner C, Engel C, Schwab M, Halliday HL, Poets CF, NEUROSIS Trial Group. Early inhaled budesonide for the prevention of bronchopulmonary dysplasia. N Engl J Med. 2015;373:1497-506.

96. Schmidt B, Roberts RS, Davis P, Doyle LW, Barrington KJ, Ohlsson A, Solimano A, Tin W, Caffeine for Apnea of Prematurity Trial Group. Caffeine therapy for apnea of prematurity. N Engl J Med. 2006;354:2112-21.

97. Schmidt B, Roberts RS, Davis P, Doyle LW, Barrington KJ, Ohlsson A, Solimano A, Tin W, Caffeine for Apnea of Prematurity Trial Group. Long term effects of caffeine therapy for apnea of prematurity. N Engl J Med. 2007;357:1893-902.

98. Dobson NR, Patel RM, Smith PB, Kuehn DR, Clark J, Vyas-Read S, Herring A, Laughon MM, Carlton D, Hunt CE. Trends in caffeine use and association between clinical outcomes and timing of therapy in very low birth weight infants. J Pediatr. 2014;164:992-8.

99. Taha D, Kirkby S, Nawab U, Dysart KC, Genen L, Greenspan JS, Aghai ZH. Early caffeine therapy for prevention of bronchopulmonary dysplasia in preterm infants. J Matern Fetal Neonatal Med. 2014;27:1698-702.

100. Lodha A, Seshia M, McMillan DD, Barrington K, Yang J, Lee SK, Shah PS, Canadian Neonatal Network. Association of early caffeine administration and neonatal outcomes in very preterm neonates. JAMA Pediatr. 2015:169:33-8.

101. Weichelt U, Cay R, Schmitz T, Strauss E, Sifringer M, Bührer C, Endesfelder S. Prevention of hyperoxia-mediated pulmonary inflammation in neonatal rats by caffeine. Eur Respir J. 2013;41:966-73.

102. Darlow BA, Graham PJ, Rojas-Reyes MX. Vitamin A supplementation to prevent mortality and short- and long-term morbidity in very low birth weight infants. Cochrane Database Syst Rev. 2016;8:CD000501.

103. Wardle SP, Hughes A, Chen S, Shaw NJ. Randomised controlled trial of oral vitamin A supplementation in preterm infants to prevent chronic lung disease. Arch Dis Child Fetal Neonatal Ed. 2001;84:F9-13.

104. Uberos J, Miras-Baldo M, Jerez-Calero A, Narbona-López E. Effectiveness of vitamin $\mathrm{A}$ in the prevention of complications of prematurity. Pediatr Neonatol. 2014;55:358-62.

105. The Neonatal Inhaled Nitric Oxide Study Group. Inhaled nitric oxide in full-term and nearly fullterm infants with hypoxic respiratory failure. $N$ Engl J Med. 1997;336:597-604.

106. Barrington KJ, Finer N, Pennaforte T. Inhaled nitric oxide for respiratory failure in preterm infants. Cochrane Database Syst Rev. 2017;1:CD000509

107. Cole FS, Alleyne C, Barks JD, Boyle RJ, Carroll JL, Dokken D, Edwards WH, Georgieff M, Gregory K, Johnston MV, Kramer M, Mitchell C, Neu J, Pursley DM, Robinson WM, Rowitch DH. Consensus development conference statement: inhaled nitric-oxide therapy for premature infants. Pediatrics. 2011;127:363-9.

108. Sokol GM, Konduri GG, Van Meurs KP. Inhaled nitric oxide therapy for pulmonary disorders of the term and preterm infant. Semin Perinatol. 2016:40:356-69.
109. Gadhia MM, Cutter GR, Abman SH, Kinsella JP. Effects of early inhaled nitric oxide therapy and vitamin A supplementation on the risk for bronchopulmonary dysplasia in premature newborns with respiratory failure. J Pediatr. 2014;164:744-8.

110. Möbius MA, Thébaud B. Bronchopulmonary dysplasia—where have all the stem cells gone? Origin and (potential) function of resident lung stem cells. Chest. 2017. https://doi.org/10.1016/j.chest.2017.04.173

\section{(Epub May 4).}

111. Sinclair K, Yerkovich ST, Chambers DC. Mesenchymal stem cells and the lung. Respirology. 2013;18:397-411.

112. Lesage F, Jimenez J, Toelen J, Deprest J. Preclinical evaluation of cellbased strategies to prevent or treat bronchopulmonary dysplasia in animal models: a systematic review. J Matern Fetal Neonatal Med. 2017. https://doi.org/10.1080/14767058.2017.1301927 (Epub ahead of print), (Epub March 21)

113. Tian ZF, Du J, Wang B, Hong XY, Feng ZC. Intravenous infusion of rat bone marrow-derived mesenchymal stem cells ameliorates hyperoxiainduced lung injury in neonatal rats. Nan fang yi ke da xue xue bao. 2007;27:1692-5.

114. van Haaften T, Byrne R, Bonnet S, Rochefort GY, Akabutu J, Bouchentouf M, Rey-Parra GJ, Galipeau J, Haromy A, Eaton F, Chen M, Hashimoto K, Abley D, Korbutt G, Archer SL, Thébaud B. Airway delivery of mesenchymal stem cells prevents arrested alveolar growth in neonatal lung injury in rats. Am J Respir Crit Care Med. 2009;180:1131-42.

115. Makhlough A, Shekarchian S, Moghadasali R, Einollahi B, Hosseini SE, Jaroughi N, Bolurieh T, Baharvand H, Aghdami N. Safety and tolerability of autologous bone marrow mesenchymal stromal cells in ADPKD patients. Stem Cell Res Ther. 2017;8:116.

116. Stolk J, Broekman W, Mauad T, Zwaginga JJ, Roelofs H, Fibbe WE, Oostendorp J, Bajema I, Versteegh MI, Taube C, Hiemstra PS. A phase I study for intravenous autologous mesenchymal stromal cell administration to patients with severe emphysema. QJM. 2016;109:331-6.

117. Weiss DJ, Casaburi R, Flannery R, LeRoux-Williams M, Tashkin DP. A placebocontrolled, randomized trial of mesenchymal stem cells in COPD. Chest. 2013;143:1590-8.

118. Simones AA, Beisang DJ, Panoskaltsis-Mortari A, Roberts KD. Mesenchymal stem cells in the pathogenesis and treatment of bronchopulmonary dysplasia: a clinical review. Pediatr Res. 2017. https://doi. org/10.1038/pr.2017.237 (Epub ahead of print), (Epub Sep 25).

119. Chang YS, Ahn SY, Yoo HS, Sung SI, Choi SJ, Oh WI, Park WS. Mesenchymal stem cells for bronchopulmonary dysplasia: phase 1 dose-escalation clinical trial. J Pediatr. 2014;164:966-72.

120. Powell SB, Silvestri JM: Safety of intratracheal transplantation of human umbilical cord derived mesenchymal stem cells (HUCB-MSCs) in extremely low birth weight (ELBW) preterm infants at highest risk for bronchopulmonary dysplasia (BPD). Pediatric Academic Societies Meeting, May 6-8, 2017, San Francisco, CA.

121. Chambers DC, Enever D, llic N, Sparks L, Whitelaw K, Ayres J, Yerkovich ST, Khalil D, Atkinson KM, Hopkins PM. A phase $1 \mathrm{~b}$ study of placentaderived mesenchymal stromal cells in patients with idiopathic pulmonary fibrosis. Respirology. 2014;19:1013-8.

\section{Submit your next manuscript to BioMed Central and we will help you at every step:}

- We accept pre-submission inquiries

- Our selector tool helps you to find the most relevant journal

- We provide round the clock customer support

- Convenient online submission

- Thorough peer review

- Inclusion in PubMed and all major indexing services

- Maximum visibility for your research

Submit your manuscript at www.biomedcentral.com/submit 